\title{
OS ESTUDOS CTS E A FILOSOFIA DA TECNOLOGIA DE ANDREW FEENBERG
}

\author{
The CTS Studies and The Philosophy of Andrew Feenberg's Technology
}

Arilson Pereira do Vale ${ }^{1}$

\begin{abstract}
RESUMO: O propósito deste trabalho é apresentar suscintamente o que são os estudos CTS (Ciência, Tecnologia e Sociedade), campo de pesquisa dedicado, entre outras, à análise crítica e interdisciplinar da interação complexa entre ciência, tecnologia e sociedade, questionando a perspectiva que pressupõe uma relação linear entre os mesmos e, por conseguinte, questionando os mitos da neutralidade da ciência e o determinismo tecnológico. Igualmente apresentaremos proposições teóricas do filósofo Andrew Feenberg, em especial sua abordagem sobre a necessidade de "democratização da tecnologia", pois, conforme Feenberg, a tecnologia é um fenômeno essencialmente social, o que nos possibilita pensar um modelo alternativo de racionalizar a sociedade em direção a formas caracterizadas pela democracia e não pelo controle autoritário.
\end{abstract}

PALAVRAS-CHAVE: Estudos CTS; Filosofia da Tecnologia; Andrew Feenberg; Neutralidade da Ciência; Determinismo Tecnológico.

ABSTRACT: The purpose of this work is to give a brief presentation of the CTS (Science, Technology and Society) studies, a field of research dedicated, among others, to the critical and interdisciplinary analysis of the complex interaction between science, technology and society, questioning the perspective that presupposes a linear relation between them and, therefore, questioning the myths of the neutrality of science and technological determinism. We will also present theoretical propositions of the philosopher Andrew Feenberg, especially his approach on the need for "democratization of technology", since, according to Feenberg, technology is an essentially social phenomenon, which allows us to think of an alternative model of rationalizing society towards to forms characterized by democracy and not by authoritarian control.

KEYWORDS: CTS studies; Philosophy of Technology; Andrew Feenberg; Neutrality of Science; Technological Determinism.

Um Projeto Alternativo de Sociedade e de Desenvolvimento deve estar fundamentado na construção da democracia como um valor fundamental e estratégico. Uma democracia radical que dê plenas condições às opções dos indivíduos e a autonomia aos grupos organizados. Isso implica, entre outras, na democracia econômica - distribuição de renda e riqueza entre todos os cidadãos, sem exclusões. Implica na democracia social - através do acesso de todos aos bens, serviços e avanços sociais da humanidade (educação, saúde, lazer, cultura, etc.). E implica na democracia cultural e na plena democracia política. A participação da sociedade nos debates, formulações, decisões e fiscalização das

\footnotetext{
1 Doutor em tecnologia pela Universidade Tecnológica Federal do Paraná (UTFPR) e professor na
} Universidade Tecnológica Federal do Paraná (UTFPR). E-mail: arilson@utfpr.edu.br 
políticas públicas e do poder público é uma condição essencial para o exercício da democracia e da cidadania e para a construção de um desenvolvimento sustentável e solidário. Por outro lado, a participação e ocupação dos espaços públicos devem ser entendidas pelos movimentos sociais como um direito e um dever democráticos.

(...)

Por fim, um Projeto Alternativo de Desenvolvimento deve basear-se na solidariedade como um valor essencial e como estratégia de construção. Os projetos de desenvolvimento com base na competição geram a exclusão e as diferenças sociais. A solidariedade social e econômica, entre povos, entre gerações, entre categorias, entre grupos sociais e entre as pessoas é uma característica da humanidade que precisa ser resgatada e reconstruída. Nesse sentido, o estímulo às diversas formas de cooperação agrícola, de articulação de grupos, de articulação entre o campo e a cidade são mecanismos fundamentais no processo de construção de um Projeto Alternativo de Desenvolvimento Sustentável e Solidário. (DESER, 2002, p. 16-17)

As citações acima transcritas são de um trabalho desenvolvido pelo DESER ${ }^{3}$ (Departamento de Estudos Sócio-Econômicos e Rurais) ao tematizar alguns elementos que caracterizariam um projeto alternativo de desenvolvimento para a agricultura familiar alicerçado na democracia, sustentabilidade e solidariedade.

Embora nosso objetivo não seja analisar o trabalho do DESER em suas pesquisas sobre agricultura familiar, os recortes acima transcritos servem de indicação sobre a temática que nos dedicaremos neste capítulo. Ou seja, o desafio de pensarmos formas de redimensionamento de um projeto de sociedade alicerçado na inclusão social, na solidariedade e na ampliação da democracia.

Para essa reflexão, nos valeremos, fundamentalmente, dos pressupostos teóricos dos "Estudos Sociais da C\&T" (ESCT) ou, simplesmente, estudos CTS, campo interdisciplinar de pesquisa que ressalta a necessidade de maior participação social nas decisões sobre a PCT (Política de Ciência e Tecnologia), além da enfática crítica às perspectivas do determinismo tecnológico e da neutralidade da ciência e da tecnologia. Também nos valeremos das proposições do filósofo da tecnologia Andrew Feenberg e sua teoria crítica da tecnologia, em especial sua abordagem sobre a necessidade da "democratização dos sistemas técnicos" com a efetiva participação da sociedade na definição e rumos do desenvolvimento científico e tecnológico.

\footnotetext{
${ }^{2}$ Grifos nossos.

3 "O Deser é uma entidade das organizações da agricultura familiar que realiza sistematização de informações, realização de pesquisas e estudos, elaboração de propostas e políticas e assessoria às organizações, movimentos, entidades e instituições vinculadas à agricultura familiar. O DESER entende que o modelo de desenvolvimento historicamente hegemônico no Brasil tem se caracterizado por ser um processo concentrador da riqueza e da terra, excludente, destruidor de valores, socialmente injusto e ambientalmente insustentável. Por isso, faz parte essencial de sua missão estratégica a contribuição, em conjunto com as organizações da agricultura familiar e com as demais entidades e instituições que lutam por mudanças estruturais, a contribuição na construção de um Projeto de Desenvolvimento, alternativo ao atual e cujas características centrais tenham por base a sustentabilidade, a democracia e a solidariedade". $<\underline{\text { http:}: / \text { www.deser.org.br/QuemSomos.asp }>}$
} 
Portanto, este trabalho buscará problematizar a necessidade de se pensar desenvolvimento e inclusão social a partir de uma maior democratização do Estado e efetiva participação da sociedade na definição das políticas e agendas públicas.

\section{Os Estudos CTS}

Os estudos CTS se desenvolvem essencialmente na tentativa de esclarecer que Ciência \& Tecnologia não são entidades autônomas e que só é possível compreendê-las enquanto fenômenos profundamente sociais, ou seja, com profundas implicações econômicas, políticas, culturais, ideológicas, ético-morais, etc.

Para Cutcliffe, os estudos CTS,

(...) tem como tema principal de estudo a explicação e análise da ciência e da tecnologia como construção social complexa (...) que implica uma multiplicidade de questões epistemológicas, políticas e éticas. Nesta visão contextual, CTS reconhece que a ciência e a tecnologia não são nem forças destruidoras completamente autônomas nem simples ferramentas neutras prontas para qualquer utilização que se requeira. Em vez disto, a ciência e a tecnologia são consideradas processos sociais carregados de valores que se produzem nos contextos históricos específicos $(\ldots)^{4}$.

Tal perspectiva e campo de estudo se contrapõem às visões e interpretações sobre a ciência e a tecnologia como conhecimentos neutros valorativamente. Essa visão positiva de neutralidade valorativa da ciência, conforme o próprio Cutcliffe, tem sua origem em princípios do século XX com o economista e sociólogo Max Weber.

Em sua luta para estabilizar a institucionalização das novas ciências sociais nas universidades alemãs, Weber enfrentou acadêmicos de esquerda que defendiam o compromisso e a implicação política e defendeu a teoria de uma ciência livre de todo tipo de valores e vinculações ideológicas e políticas ${ }^{5}$.

No entanto, conforme o mesmo autor (2003), a partir de finais da década de 1960, em especial nos EUA e posteriormente na Europa, esse conjunto de pressupostos filosóficos foi posto em questionamento a partir do contexto dos movimentos anti-nucleares, da oposição à Guerra do Vietnã e da crise ecológica. Surgiram, então, programas CTS em diversas universidades dos EUA que passaram a refletir sobre os condicionamentos políticos, sociais e valorativos no desenvolvimento científico e tecnológico e alertar para os graves impactos do mesmo sobre a sociedade e o meio ambiente. Igualmente passaram a questionar o conceito de progresso alicerçado na perspectiva linear de desenvolvimento científico e tecnológico.

Os grupos de ativistas, reivindicando falar em nome dos interesses públicos em áreas como o consumo, os direitos civis e o meio ambiente, junto com as manifestações de protesto contra a Guerra do Vietnã,

\footnotetext{
${ }^{4}$ CUTCLIFFE, Stephen H. Ideas, máquinas y valores: Los estúdios de ciência, tecnologia y sociedade. Barcelona: Anthropos Editorial, 2003, p. 2.

${ }^{5}$ Ibidem, p. XI.
} 
as empresas multinacionais e a energia nuclear, entre outros temas, marcaram grande parte do contexto geral deste período ${ }^{6}$.

Da mesma forma, no meio acadêmico houve reações daqueles ligados às interpretações epistemológicas da filosofia analítica, acusando o movimento CTS de pseudocientífico e irracional e defendendo a excelência racional e a neutralidade valorativa do conhecimento científico. Ou seja, não admitindo a abordagem que interpreta a ciência e a tecnologia enquanto construções sócio-históricas.

Destaca-se nesse contexto o filósofo da ciência Mario Bunge ${ }^{7}$ que declarou uma verdadeira "guerra" (Science Wars) aos estudos CTS. Assim comenta Cutcliffe sobre Bunge:

Segundo sua visão de Science Wars, a partir de meados dos anos 60 se infiltraram, em muitas universidades dos EUA, inimigos anti-ciência e pseudo-científicos que "construíram um cavalo de Troia dentro da vida acadêmica com a intenção de destruir de dentro a cultura superior". Entre esses inimigos se destacam os representantes da nova filosofia e da sociologia da ciência, desobedientes, segundo Bunge, pela influência das teorias marxistas. Para Bunge, se trata, na realidade, de "charlatões acadêmicos" que deveriam ser expulsos dos "templos do ensino superior" antes que possam minar a civilização moderna conduzindo-nos a uma nova Idade das Trevas. Tendo em conta a gravidade da situação, o filósofo da ciência faz um chamamento de guerra a "todos os genuínos intelectuais" para que se alistem no "Esquadrão da Verdade" e lutem para desmantelar o cavalo de Troia que quer acabar com a Academia ${ }^{8}$.

Essa contundente reação de Bunge em sua "Science Wars" revela os mitos positivistas que guiaram o desenvolvimento científico por muito tempo e ainda hoje circundam o meio acadêmico. Mitos que servem muito mais aos interesses da própria academia do que ao conjunto da sociedade. São eles:

- O mito do benefício infinito: mais ciência e mais tecnologia conduzem a mais benefícios sociais;

- O mito da autoridade: a informação científica proveem de uma base objetiva para resolver disputas políticas;

- O mito da fronteira sem limites: os novos conhecimentos gerados nas fronteiras da ciência são autônomos com respeito às consequências morais e práticas na sociedade ${ }^{9}$.

\footnotetext{
${ }^{6}$ Ibidem, p.8.

${ }^{7}$ Mário Augusto Bunge é físico e filósofo da ciência nascido na Argentina em 1919. Possui doutorado em Física e Matemática pela Universidade de La Plata e estudou Física Nuclear no Observatório Astronômico de Córdoba. Lecionou Física e Filosofia na Universidade de Buenos Aires entre os anos de 1957-1962 e foi professor de filosofia na McGill University de Montreal-Canadá desde 1962. É defensor do realismo científico e conhecido por suas contundentes críticas às chamadas "pseudociências", à psicanálise e ao pósmodernismo. Sua abordagem critica o chamado "relativismo epistemológico" das análises construtivistas que estariam desconsiderando a dimensão ontológica do conhecimento científico. Sua principal obra é o "Tratado de Filosofia Básica" (1974-1989), composto por 8 volumes. Entre seus Ensaios mais destacados podemos citar "Racionalidade e Realismo" (1985), onde, a partir de uma análise formal do desenvolvimento científico, proclama a supremacia da ciência sobre todos os demais tipos de conhecimento. In: $<$ http://www.biografiasyvidas.com/biografia/b/bunge.htm>

${ }^{8}$ CUTCLIFFE. Op. Cit., 2003, p. XIV.

${ }^{9}$ Ibidem, p. XV.
} 
Igualmente na América Latina, o surgimento deste campo de investigação e estudos em CTS, onde se tem a percepção da ciência e da tecnologia em sua estreita relação com a sociedade, se situa entre o final dos anos 60 e princípios dos anos 70. A percepção clássica de C\&T que se tinha até este período se caracterizava por uma concepção essencialista e triunfalista expressa num "modelo linear de desenvolvimento", ou seja,

(...) Ciência e tecnologia são apresentadas como formas autônomas da cultura, como atividades valorativamente neutras, como uma aliança heróica de conquista cognitiva e material da natureza. (...) $\mathrm{O}$ bem-estar nacional depende do financiamento da ciência básica e do desenvolvimento sem interferência da tecnologia, assim como da necessidade de manter a autonomia da ciência para que o modelo funcione. O crescimento econômico e o progresso social viriam por conseqüência ${ }^{10}$.

Conforme Dagnino, Davyt e Thomas (1996), até a década de 50 a América Latina seguiu o Modelo Linear de Inovação ${ }^{11}$ onde se considerava que o desenvolvimento científico e tecnológico era condição necessária e suficiente, para a geração de desenvolvimento econômico e social dos países periféricos. Somente a partir dos estudos do PLACTS (Pensamento Latino Americano em Ciência, Tecnologia e Sociedade) é que se procurou dar ênfase aos aspectos históricos e políticos do desenvolvimento em ciência e tecnologia e pensar um modelo alternativo ao modelo linear de desenvolvimento.

As estratégias propostas por esses pensadores ${ }^{12}$ propunham desde uma política de C\&T como ferramenta para a instauração revolucionária do socialismo ${ }^{13}$ ou como aspecto integrante de uma estratégia nacional desenvolvimentista ${ }^{14}$. Porém, comum é a ênfase dada à relação dos aspectos históricos, políticos e sociais com a C\&T.

Em última instância, o PLACTS propõe que se faça uma inversão do Modelo Institucional Ofertista Linear (MIOL), movido por uma lógica ofertista, mediante a construção de um projeto nacional de desenvolvimento econômico e social dos países da

10 BAZZO, Walter; LINSINGEN, Irlan von \& PEREIRA, Luiz Teixeira do Vale. Os estudos CTS. In Introdução aos Estudos CTS (Ciência, Tecnologia e Sociedade). Espanha: OEI, 2003, p.120-122.

11 “O modelo linear de inovação não leva em conta os fatores sociais que levam ao desenvolvimento de determinadas soluções em detrimento de outras, nem o fato de que essas opções possuem, via de regra, forte viés econômico e/ou político." In: $<$ http://placts.org/>

12 Dentre os principais pensadores desta corrente podemos citar os argentinos Oscar Varsavsky, Amilcar Herrera e Jorge Sábato; Miguel Wionczek no México; Francisco Sagasti no Perú; Máximo Halty Carrere no Uruguai; Marcel Roche na Venezuela e José Leite Lopes no Brasil. Nesse mesmo contexto histórico e alinhados com as preocupações e reflexões do PLACTS, podemos igualmente citar os brasileiros Álvaro Vieira Pinto e Darcy Ribeiro.

${ }^{13}$ Em "Estilos tecnológicos: propuestas para la selección de tecnologías bajo racionalidad socialista" (1974), Oscar VARSAVSKY afirma que não há um único estilo de desenvolvimento e, consequentemente, uma única C\&T. Mostrava, então, a íntima relação entre estilo de desenvolvimento e a produção científicotecnológica. Então, conclui pela proposta revolucionária de mudança do sistema pela promoção de outro tipo de sociedade baseada em outro estilo de desenvolvimento e, consequentemente, outra C\&T.

14 Jorge SABATO, conhecido por seu pragmatismo, foi o intelectual vinculado ao PLACTS com maior inserção política. Sua sistematização sobre política de C\&T, conhecido por "Triângulo de Sabato", postula a necessidade de um 'triângulo de relações entre governo, setor produtivo e complexo científicotecnológico’ como modelo de política de C\&T. Ver: SABATO, Jorge A. \& BOTANA, Natalio. (2011). 
América Latina, pois as inovações tecnológicas não são socialmente neutras e naturalmente promotoras de desenvolvimento.

Nesse contexto de reflexão, os estudos em CTS apontam na direção da necessidade de “(...) regulação social da ciência e da tecnologia, promovendo a criação de diversos mecanismos democráticos que facilitam a abertura de processos de tomada de decisão em questões concernentes a políticas científico-tecnológicas" ${ }^{15}$. Ou seja, a participação cidadã e democrática na definição, regulação e gestão das políticas públicas sobre ciência e tecnologia, passa a ser considerada fator essencial para pensar C\&T enquanto fenômeno profundamente social.

Contrária a esta perspectiva se situaria a visão tecnocrática que afirma ser a ciência uma instituição autônoma e objetiva. Nela, portanto, o público não deveria e não teria condições de se envolver na gestão desse conhecimento, deixando assim tal gerenciamento àqueles que tem condições de uma ação mais racional e adequada. Essa perspectiva expressa uma determinada concepção epistemológica de ciência e tecnologia que as conduziu e caracterizou, até então, como atividades pretensamente neutras e ao mesmo tempo determinísticas da realidade. Apesar das dificuldades que se apresentam ao pensar na participação cidadã e na gestão democrática das políticas públicas em ciência e tecnologia, é justamente em razão dessa concepção tecnocrática, determinista e de pretensa neutralidade que se situa o grande desafio de nosso tempo, o qual seja, conforme Feenberg (2002), o de uma profunda revisão epistemológica da natureza da ciência e da tecnologia.

\section{Andrew Feenberg}

Andrew Feenberg é um dos mais renomados estudiosos da filosofia da tecnologia, procurando discutir, com sua "Teoria Crítica da Tecnologia", a estreita relação entre tecnologia e sociedade. Feenberg problematiza, fundamentalmente, em sua obra o que podemos chamar de perspectiva ideológica e perspectiva crítica da tecnologia.

Essas perspectivas, ideológica e crítica, aqui apresentadas, são o resumo das "Quatro Visões sobre a Tecnologia" (determinismo-instrumentalismo-substantivismo-teoria crítica) elaborado e discutido por Dagnino (2008, p. 241) com base nas proposições de Andrew Feenberg.

\footnotetext{
${ }^{15}$ BAZZO. Op. Cit., 2003, p. 127.
} 


\section{Quadro 1: Quatro visões sobre a Tecnologia}

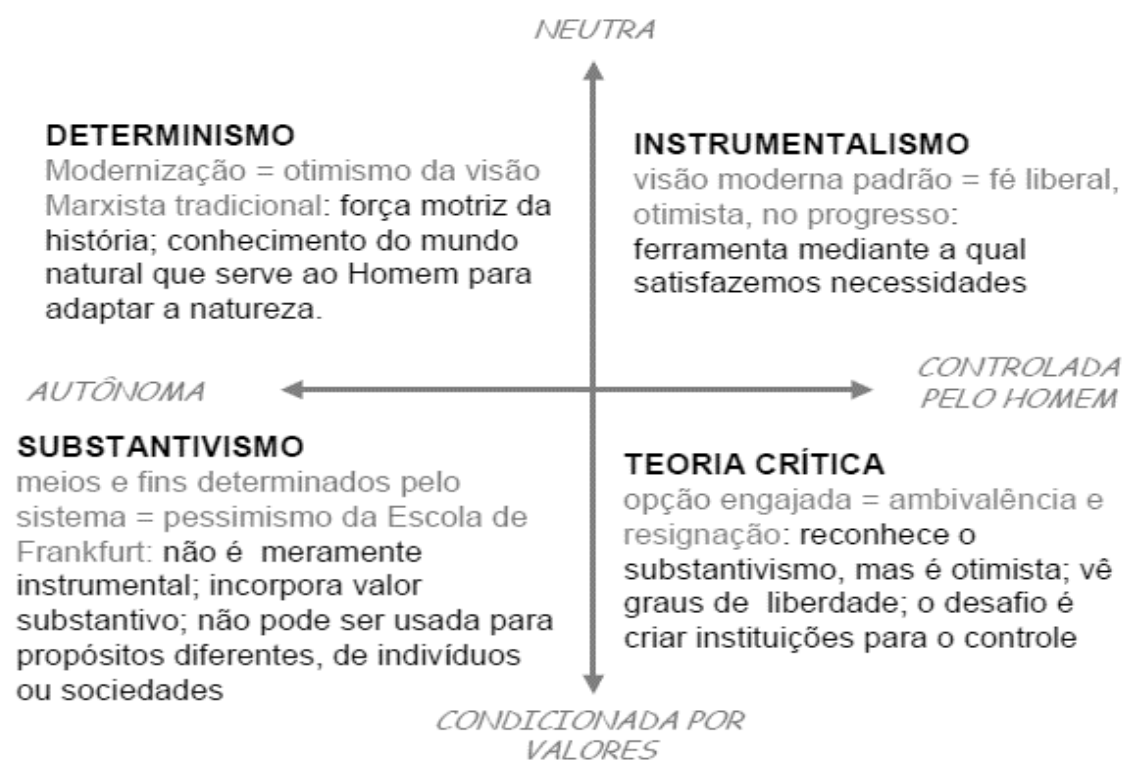

Fonte: Elaborado por Dagnino (2008, p.241) a partir das proposições de Andrew Feenberg.

$\mathrm{Na}$ primeira perspectiva, a tecnologia é abordada segundo uma interpretação utilitarista, onde se parte de uma pretensa neutralidade da mesma e seu conseqüente mero uso instrumental. Como exemplo, temos a visão positivista e mecanicista do significado da tecnologia, própria dos discursos de tradição liberal que insistem em afirmar pela trajetória ascendente do desenvolvimento tecnológico e dissociá-lo de suas dimensões sócio-econômico-políticas. Tal perspectiva ideológica também se insere nos discursos, crenças e práticas sociais que associam o desenvolvimento social a um "natural" desenvolvimento da tecnologia, considerada enquanto força motriz da história. Neste caso temos, como exemplo, o otimismo marxista diante da tecnologia e uma conseqüente perspectiva determinista sobre o seu significado expressa numa racionalidade funcional que, igualmente, a dissocia das dimensões sócio-econômico-políticas. ${ }^{16}$

\footnotetext{
${ }^{16}$ Novaes (2007, p.96-97), descreve a compreensão que muitos marxistas tinham e têm em considerar as forças produtivas, em especial a ciência e a tecnologia, como ideologicamente neutras com um desenvolvimento intrinsecamente positivo. Cita então Bryan $(1985$, p.51) em análise sobre a Segunda e Terceira Internacional, que afirmava que da contradição entre as Relações Sociais de Produção (RSP) e as Forças Produtivas (FP), chegaríamos a um momento em que “(...) as forças produtivas libertar-se-iam do casulo das relações sociais capitalistas, nas quais se encontram presas, e seriam postas a serviço das necessidades sociais, constituindo o suporte de uma nova sociedade livre dos flagelos das crises periódicas, do desperdício e miséria, possibilitando o livre desenvolvimento da humanidade".
} 
Na segunda perspectiva, a tecnologia adquire a compreensão de sua estreita relação com as razões do sistema como, por exemplo, a abordagem pessimista da Escola de Frankfurt e o significado de uma razão instrumental que configura a lógica do sistema capitalista e submete o desenvolvimento tecnológico às intenções do capital ${ }^{17}$.

Igualmente nesta segunda perspectiva se insere a "Teoria Crítica da Tecnologia" de Feenberg, que “(...) reconhece as conseqüências catastróficas do desenvolvimento tecnológico ressaltadas pelo substantivismo (Escola de Frankfurt)"18, porém vê na tecnologia uma promessa de liberdade. Aposta na visão otimista quanto ao desenvolvimento de formas de controle e no desafio de criar meios para o fortalecimento e esclarecimento do papel das instituições técnicas e da sociedade. Assim, afirma Feenberg: "Precisamos desenvolver uma teoria que considere o crescente peso dos atores públicos no desenvolvimento tecnológico"19.

Ou seja, o diálogo filosófico de Feenberg é orientado para os sujeitos sociais capazes de uma ação social e política de democratização dos sistemas técnicos e em oposição a toda manifestação determinista que nega a relação dos fatores técnicos e sociais no desenvolvimento tecnológico, pois, segundo ele, tais enunciados deterministas são “(...) definições tendenciosas, que fazem a tecnologia parecer mais funcional e menos social do que de fato é" 20 .

Podemos afirmar que Feenberg enfatiza os aspectos contextuais da tecnologia em contraposição à versão descontextualizada do determinismo tecnológico ${ }^{21}$, em que a

\footnotetext{
17 Nesta perspectiva Habermas afirma: "Os princípios da ciência moderna foram estruturados aprioristicamente, de tal modo que puderam servir de instrumentos conceituais para um universo de controles produtivos efetuando-se automaticamente: o operacionalismo teórico passou a corresponder ao operacionalismo prático. Assim, o método científico que levou à dominação cada vez mais eficaz da Natureza, forneceu tanto os conceitos puros quanto os instrumentos para a dominação cada vez maior do homem por meio da dominação da Natureza. A razão teórica, permanecendo pura e neutra, colocou-se a serviço da razão prática (...) Hoje, a dominação se perpetua e se estende, não apenas através da tecnologia, mas enquanto tecnologia, e esta garante a grande legitimação do crescente poder político que absorve todas as esferas da cultura. Nesse universo, a tecnologia também garante a grande racionalização da não-liberdade do homem e demonstra a impossibilidade "técnica" de a criatura ser autônoma, de determinar sua própria vida (...). A racionalidade tecnológica protege, assim, em vez de cancelar, a legitimidade da dominação; e o horizonte instrumental da razão se abre para uma sociedade racionalmente totalitária." (HABERMAS, 1975, p. 305).

${ }^{18}$ DAGNINO, Renato Peixoto. Neutralidade da Ciência e Determinismo Tecnológico: um debate sobre a tecnociência. Campinas, SP: Editora da Unicamp, 2008, p. 214.

${ }^{19}$ In: NEDER, Ricardo T. (org). A teoria crítica de Andrew Feenberg: racionalização democrática, poder e tecnologia. Brasília: Observatório do Movimento pela Tecnologia Social na América Latina / CDS / UnB / Capes, 2010 (1. ed.) 2013 (2. ed.) 4. 2013, p. 198.

${ }^{20}$ Ibidem, p. 76.

${ }^{21}$ Sobre este aspecto Dagnino comenta: "No que respeita ao determinismo tecnológico, a ideia é a de que o desenvolvimento da tecnociência é uma variável independente e universal que determinaria o comportamento de todas as outras variáveis do sistema produtivo e social - como se ela dependesse inteiramente das mudanças e da organização tecnológicas. O desenvolvimento econômico é determinado
} 
tecnologia aparece como auto-geradora e único fundamento da sociedade moderna. Sua teoria, em última instância, está comprometida com a democratização da tecnologia e das instituições técnicas.

Acredita-se amplamente que a sociedade tecnológica está condenada à administração autoritária, ao trabalho irracional, e ao consumo igualmente irracional. As críticas sociais afirmam que a racionalidade técnica e os valores humanos competem pela alma do homem moderno. Este livro desafia tais clichês concebendo novamente a relação da tecnologia, racionalidade e democracia. A minha tese é a possibilidade de uma reforma verdadeiramente radical da sociedade industrial. (...) Eu argumento que a degradação do trabalho, da educação e do ambiente está enraizada não na tecnologia per se, mas em valores antidemocráticos que governam o desenvolvimento tecnológico. (...) Uma sociedade boa deveria aumentar a liberdade pessoal de seus membros ao mesmo tempo em que os habilita para participar efetivamente em um crescente número de atividades públicas. Num nível mais elevado, a vida pública envolve escolhas sobre o que significa ser humano. Hoje estas escolhas são crescentemente mediadas pelas decisões técnicas ${ }^{22}$.

Valores antidemocráticos que governam o desenvolvimento tecnológico, inscritos na racionalidade tecnológica materializada em artefatos, diretrizes e políticas tecnológicas, são uma característica particular de nossa sociedade capitalista e não uma dimensão universal da modernidade.

Ao desenvolver tal abordagem, Feenberg elabora o conceito de "racionalização

subversiva" em oposição ao conceito de racionalização em Weber. Assim afirma:

(...) A racionalização na nossa sociedade responde a uma definição particular de tecnologia como um meio para obter lucro e poder. Uma compreensão mais abrangente da tecnologia sugere uma noção muito diferente de racionalização, baseada na responsabilidade da ação técnica quanto aos contextos humanos e naturais. Chamo isso "racionalização subversiva", porque requer avanços tecnológicos que só podem ocorrer em oposição à hegemonia dominante, o que representa uma alternativa à celebração contínua da tecnocracia triunfante, quanto à escura contrapartida Heideggeriana que "apenas um deus pode nos salvar" de um desastre tecnocultural ${ }^{23}$.

Weber definiu racionalização como o papel crescente do controle da vida social, confundindo, segundo Feenberg, o controle do trabalho pelo gerenciamento com o controle da natureza pela tecnologia. Porém, para Feenberg o desenho das máquinas é socialmente relativo e a racionalidade tecnológica que ela incorpora não é universal, mas particular ao capitalismo ${ }^{24}$.

pelo avanço da tecnociência, e esta é um determinante da estrutura social e a força condutora do progresso social." (DAGNINO, 2014, p. 51).

${ }^{22}$ FEENBERG. As variedades de Teoria - Tecnologia e o Fim da História. O presente texto é a introdução do livro Transforming technology. A critical Theory revisited. New York: oxford University Press, 2002, p. 1 .

${ }^{23}$ FEENBERG. In: NEDER, Ricardo T. (org). A teoria crítica de Andrew Feenberg: racionalização democrática, poder e tecnologia. Brasília: Observatório do Movimento pela Tecnologia Social na América Latina / CDS / UnB / Capes, 2010 (1. ed.), p. 98.

${ }^{24}$ Ver "Decca (1986), em "O Nascimento das Fábricas", e sua análise sobre o papel do relógio na construção ideológica do controle do tempo como fundamental no processo de consolidação do sistema capitalista. "(...) a Revolução Industrial foi vitoriosa, uma vez que representou uma mudança crucial não apenas no aparato técnico produtivo, mas, principalmente, nas estratégias de administração das empresas fabris. Em outras palavras, o êxito da revolução estava intimamente ligado à afirmação de novas relações de poder hierárquicas e autoritárias. (DECCA, 1986, p. 30)". No mesmo sentido, afirma (NOVAES, 2005, 
Da mesma forma, estende sua crítica às formulações de Heidegger que são falhas na medida em que identificam a tecnologia em geral com as tecnologias específicas que se desenvolveram no último século no ocidente. Tal tipo de tecnologia não é uma dimensão universal da modernidade, mas uma característica particular de nossa sociedade. Conforme Feenberg (2010), Heidegger vê a tecnologia exclusivamente como um sistema de controle e não percebe sua dimensão social com profundas implicações emancipadoras, negligenciando, assim, o papel que a mesma tem na vida daqueles que são subordinados.

(...) Heidegger depende de uma definição estreita de tecnologia que, pelo menos desde Bacon e Descartes, tem enfatizado sua vocação de controlar o mundo, excluindo o seu igualmente essencial contexto de inserção. Acredito que esta definição reflete o ambiente capitalista no qual a tecnologia moderna, primeiramente, se desenvolveu. (...) $\mathrm{O}$ estreito foco da tecnologia moderna satisfaz às necessidades de uma hegemonia particular; não é uma condição metafísica. (...) A hegemonia que se encarnou na própria tecnologia deve ser questionada na luta pela reforma tecnológica ${ }^{25}$.

Tal reforma tecnológica demanda a compreensão de que a tecnologia se adapta às mudanças sociais e que os códigos técnicos são estabelecidos no horizonte cultural da sociedade e se refletem no desenho técnico do objeto ${ }^{26}$ e, portanto, a tecnologia não é “(...) um mero meio para se chegar a um fim: padrões de desenho técnico definem partes principais do ambiente social, tais como espaços urbanos e construções, ambientes de trabalho, atividades e expectativas médicas, estilos de vida e assim por diante"27.

Portanto, o desenvolvimento tecnológico não é incompatível com o desenvolvimento humano-sócio-ambiental, é somente incompatível enquanto subordinado às demandas capitalistas hegemônicas, sendo que as resistências sociais são capazes do estabelecimento de um novo design técnico. Assim afirma Feenberg:

O que os seres humanos são e o que eles serão é decidido na configuração de nossas ferramentas tanto quanto das ações dos estadistas e dos movimentos políticos. O design da tecnologia é, portanto, uma decisão ontológica carregada de conseqüências políticas. A exclusão de uma ampla maioria da participação nesta decisão é profundamente antidemocrática. Uma mudança fundamental exige uma transformação democrática da tecnologia ${ }^{28}$.

p. 8): “(...) ao introduzir inovações, o capitalista não estaria buscando só a acumulação de capital, mas também o controle do processo de produção no interior da empresa. (...) A manutenção do controle técnico não seria então o efeito de um imperativo tecnológico, mas da maximização do poder de classe sob as circunstâncias especiais de sociedades capitalistas”. E ainda Dagnino (2011, p.38/39) “(...) aquilo que caracteriza a tecnociência não é apenas a propriedade privada dos meios de produção, mas o tipo de controle que esta determina ou faculta".

${ }^{25}$ FEENBERG. Op. Cit., 2010, p. 92.

${ }^{26}$ Ver: PINCH, Trevor J.; BIJKER, Wiebe (2008). A partir da abordagem do "Construtivismo Social" ou da "Construção Sociotécnica", estes autores analisam o objeto técnico "bicicleta" gerado a partir da "flexibilidade interpretativa" e do jogo de poder dos "grupos sociais relevantes". Ou seja, o entendimento sobre o desenvolvimento de um artefato tecnológico se dá na análise do contexto sociopolítico e da relação de forças entre os diversos grupos com ele envolvidos.

${ }^{27}$ FEENBERG. Op. Cit., 2010 , p. 90.

${ }^{28}$ FEENBERG. Op. Cit., 2002, p. 1. 
Como afirma Cutcliffe: “(...) todos os artefatos, devido a seu desenho e natureza, expressam relações de poder e autoridade de uma forma ou outra"29.

Ou seja, conforme Feenberg, precisamos entender a tecnologia como um dinâmico processo de construção social em que valores, convicções e pressões político-econômicas “dialogam" na tentativa de consolidação de interesses vários. Portanto, os artefatos tecnológicos e as respostas científico-tecnológicas expressam e carregam significados resultantes desse dinâmico processo de afirmação dos mesmos interesses.

Desta maneira, a tecnologia é então essencialmente social e carrega, potencialmente, implicações emancipadoras, o que significa afirmar que os interesses sociais ou os valores culturais influenciam a concretização dos princípios técnicos. E, se a hierarquia social autoritária é uma dimensão contingente do progresso técnico, “(...) deve haver um modo alternativo de racionalizar a sociedade que leve à democracia em lugar de formas centralizadas de controle" $" 30$.

Nós podemos conceber uma sociedade industrial baseada na participação democrática em que a liberdade individual não seja a liberdade de mercado, e em que a responsabilidade social não seja exercida através de uma regulamentação coercitiva ${ }^{31}$.

Da mesma forma afirma Novaes: "Por ser um processo inerentemente social, o desenvolvimento tecnológico tem uma larga medida de indeterminação e pode ser redirecionado" 32 . O mesmo autor comenta que:

A importância política da posição de Feenberg é clara: se existem sempre muitas potencialidades técnicas que se vão manter inexploradas, não são os imperativos tecnológicos os que estabelecem a hierarquia social existente. A tecnologia passa então a ser entendida como um espaço de luta social no qual projetos políticos alternativos estão em pugna e, o desenvolvimento tecnológico, como delimitado pelos hábitos culturais enraizados na economia, ideologia, religião e tradição. (NOVAES, 2005, p.9)

David Noble (2000), alerta, porém, que é necessário reconhecer a assimetria de poder de classes, apesar do caráter de indeterminação que possui o desenvolvimento tecnológico.

Existe uma guerra, mas só um dos lados está armado: esta é a essência da questão da tecnologia hoje. De um lado está o capital privado, científico e subvencionado, móvel e global, e na atualidade fortemente armado, com um amplo controle militar e tecnologias de comunicação. (...) Do outro lado, os que sofrem a agressão abandonam apressadamente o campo de batalhas porque carecem de um plano, de armas ou exército. Sua própria compreensão e capacidade crítica, confundidas por uma barreira intelectual, os leva a se refugiar em estratégias que oscilam entre o apaziguamento e o pacto, a incredulidade e a falsa ilusão, e a titubear, desesperados e desorganizados, ante o aparentemente inexorável ataque da mudança tecnológica (NOBLE, 2000, p.6)

\footnotetext{
${ }^{29}$ CUTCLIFFE. Op. Cit., 2003, p. 48.

${ }^{30}$ FEENBERG, In NEDER. Op. Cit., 2013, p.71.

${ }^{31}$ FEENBERG, Op. Cit., 1995, p.2.

${ }^{32}$ NOVAES. Op. Cit., 2010, p.68.
} 
Enfim, é nessa perspectiva de análise que aponta os limites das concepções sobre a pretensa neutralidade da ciência e sobre o determinismo tecnológico, que os estudos CTS dedicam-se a pensar novos horizontes para a elaboração de políticas de ciência e tecnologia para a América Latina. E, conforme Dagnino, a leitura de Feenberg nos permite compreender melhor a capacidade científica da América Latina e pode fornecer uma direção para as políticas de C\&T da América Latina.

(...) a obra de Feenberg permite aos latino-americanos que assimilaram e consideram pertinente a crítica anti-imperialista do PLACTS situá-la dentro de um contexto mais abrangente da crítica anti-capitalista. (...) A obra de Feenberg renova e fortalece o PLACTS, colocando-o como uma alternativa às interpretações que, baseadas na Teoria da Inovação e influenciadas pelo neoliberalismo, se têm enraizado em nosso meio. Ainda mais significativa do que sua contribuição descritivo-explicativa é a que propõe no plano normativo. Ao criticar as concepções Instrumental, Determinista e Substantivista da tecnologia (Feenberg, 1991, 1999, 2002), ela abre passo à formulação de uma PCT diferente da atualmente em curso, que leve ao reprojetamento da tecnologia das empresas e o desenvolvimento de tecnologias orientadas à inclusão social ${ }^{33}$.

Neste sentido Dagnino (In: NEDER, 2013) afirma que a obra de Feenberg incorpora o político e o ideológico ao tecnológico e assim nos ajuda a pensar no desenvolvimento de uma política de Ciência \& Tecnologia como elemento de luta contra a desigualdade e pela promoção da inclusão social.

\section{Conclusão}

Neste trabalho buscamos apresentar alguns fundamentos teóricos discursivos sobre os estudos CTS sobre PCT e a contribuição fundamental que a filosofia da tecnologia de Andrew Feenberg fornece a esse campo de estudos.

Nosso entendimento é de que a Teoria Crítica da Tecnologia de Feenberg amplia a perspectiva de reflexão e de análise sobre a complexa e dinâmica relação entre ciência, tecnologia e sociedade a partir, fundamentalmente, dos conceitos de democratização dos sistemas técnicos, racionalização subversiva e design técnico.

Ao incorporar o elemento da análise política à análise do fenômeno tecnológico, Feenberg amplia nossa percepção sobre formas de resistência para ampliação da democracia e da cidadania. Igualmente nos fornece elementos para situarmos a tecnologia como fenômeno essencialmente social e espaço de luta contra hegemônica, fortalecendo assim as reflexões críticas que nos ajudam a questionar os mitos da neutralidade da ciência, o determinismo tecnológico e a perspectiva linear de desenvolvimento.

${ }^{33}$ DAGNINO, In: NEDER. Op. cit., 2013, p. 27. 


\section{Referências}

BAZZO, Walter; LINSINGEN, Irlan von \& PEREIRA, Luiz Teixeira do Vale. (2003). Os estudos CTS. In Introdução aos Estudos CTS (Ciência, Tecnologia e Sociedade). Espanha: OEI, 2003.

CUTCLIFFE, Stephen H. Ideas, máquinas y valores: Los estúdios de ciência, tecnologia y sociedade. Barcelona: Anthropos Editorial, 2003.

DAGNINO, Renato Peixoto. Neutralidade da Ciência e Determinismo Tecnológico: um debate sobre a tecnociência. Campinas, SP: Editora da Unicamp, 2008.

. Ciência e Tecnologia no Brasil - O processo decisório e a comunidade de pesquisa. Campinas, SP: Editora da Unicamp, 2007.

(Org.). Tecnologia Social - ferramenta para construir outra sociedade.

2.ed. rev. e ampl. Campinas, SP: Komedi, 2010.

DAGNINO, Renato; DAVIT, Amilcar;THOMAS, Hernán (1996). El Pensamiento en Ciencia, Tecnología y Sociedad en Latinoamérica: una interpretación política de su trayectoria. Redes, 7(6), p. 13-51.

DECCA, Edgar de. O Nascimento das Fábricas. 4.ed. São Paulo: Brasiliense, 1986. (Coleção Tudo é História)

FEENBERG, Andrew. Transforming technology: Oxford University Press, 2002. . As variedades de Teoria - Tecnologia e o Fim da História. O presente texto é a introdução do livro Transforming technology. A critical Theory revisited. New York: oxford University Press, 2002, p. 3-35. Tradução Carlos Alberto Jahn.

Disponível em: www.sfu.ca/.../Portug_Chapter 1 Transforming Technology.pdf pp.128. Acesso em 11 de outubro de 2011.

. Ciencia, tecnologia y democracia: distinciones y conexiones.

SCIENTIAE Studia, São Paulo, v. 7, n.1, p. 63-81, 2009.

In: NEDER, Ricardo T. (org). A teoria critica de Andrew Feenberg: racionalização democrática, poder e tecnologia. Brasília: Observatório do Movimento pela Tecnologia Social na América Latina / CDS / UnB / Capes, 2010 (1 ${ }^{\mathrm{a}}$ ed.) 2013 ( $2^{\mathrm{a}}$ ed.) 4. 2013. ISSN 2175-2478.

HABERMAS, Jürgen. Técnica e Ciência como Ideologia. 1. ed. v. 48. São Paulo: Abril Cultural, 1975. (Coleção Os Pensadores)

NEDER, Ricardo T. (org). A teoria crítica de Andrew Feenberg: racionalização democrática, poder e tecnologia. Brasília: Observatório do Movimento pela Tecnologia Social na América Latina / CDS / UnB / Capes, 2010 (1. ed.) 2013 (2. ed.) 4. 2013. ISSN 2175-2478. 
NOBLE, David. Uma visión diferente del progresso: Em defensa del luddismo. Barcelona: Alikornio, 2000.

NOVAES, Henrique Tahan. O Fetiche da Tecnologia - a experiência das Fábricas Recuperadas. São Paulo: Expressão Popular- Fapesp, 2007.

PINCH, Trevor \& BIJKER, Wiebe. La construcción social de hechos y de artefactos: o acerca de cómo la sociología de la ciencia y la sociología de la tecnología pueden beneficiarse mutuamente. In. Thomas, H. \& Buch, A. (eds) Actos, actores y artefactos. Sociología de la tecnología. Quilmes: Universidad Nacional de Quilmes, 2008.

SABATO, Jorge A. \& BOTANA, Natalio. La ciencia y la tecnología en el desarrollo futuro de América Latina. In: SABATO, Jorge A. (org.). El pensamiento latinoamericano en la problemática ciencia-tecnología-desarrollo-dependencia. Colección PLACTED. Buenos Aires: Ediciones Biblioteca Nacional, 2011. p. 215-231.

VARSAVSKY, Oscar. Estilos tecnológicos : propuestas para la selección de tecnologías bajo racionalidad socialista / Oscar Varsavsky; con prólogo de Ruth Ladenheim y Horacio L. González. - 1a ed. - Buenos Aires : Biblioteca Nacional, 2013. 